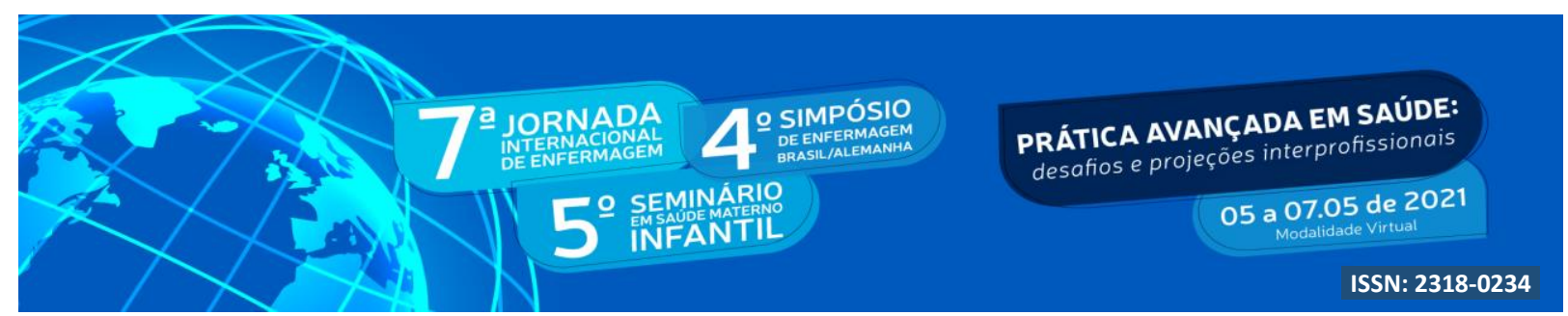

DOI: http://doi.org/10.48195/jie2021-121

\title{
HIV NA GESTAÇÃO, PARTO E PUERPÉRIO: APRESENTAÇÃO, CONCEITO E TRATAMENTO. ${ }^{1}$
}

\section{Kelvin Leandro Marques Monçalves²; Jonas Quadros³; Munah Saleh Ahmad Maruf ${ }^{4}$; Cláudia Maria Gebert Diaz .}

\begin{abstract}
RESUMO
$\mathrm{O}$ presente trabalho tem por objetivo compreender o tratamento às gestantes, o manejo do parto e o período do puerpério em mulheres soropositivas sobre o olhar do profissional da saúde. O presente estudo trata-se de uma revisão bibliográfica onde foram analisados 13 artigos utilizando as bases de dados Lilacs e PubMed tendo sido excluídos 6 por não enfocarem o Vírus da Imunodeficiência Humana na gestação, parto e período puerperal, 2 manuais técnicos do Ministério da Saúde, contando também com 1 artigo de periódicos da Universidade Federal do Amapá e 1 artigo de periódicos da Pontifícia Universidade Católica do Rio Grande do Sul. Quando a Síndrome da imunodeficiência Humana foi descoberta na década de 1980, acreditava-se tratar de uma doença restrita a apenas alguns grupos sociais. Com o passar do tempo, descobriu-se por meio da ciência que poderia infectar qualquer ser humano, independente da raça, cor, idade e do sexo que pratiquem. Mostra-se a importância de uma equipe preparada para atender as demandas de mães com sorologia positiva, a tomada de decisão na hora do parto e o manejo do cuidado para com elas durante o período do parto e período puerperal.
\end{abstract}

Palavras-chave: Gestante; HIV; Parto.

\begin{abstract}
This study aims to understand the treatment of pregnant women, the management of childbirth and the puerperium period in HIV-positive women from the perspective of the health professional. The present study is a bibliographic review in which 13 articles were analyzed using the Lilacs and PubMed databases and 6 were excluded because they did not focus on the Human Immunodeficiency Virus during pregnancy, childbirth and the puerperal period and 2 technical manuals from the Ministry of Health, also featuring 1 article from periodicals at the Federal University of Amapá and 1 article from periodicals at the Pontifical Catholic University of Rio Grande do Sul. When the Human Immunodeficiency Syndrome was discovered in the 1980s, it was believed to be a disease restricted to only a few social groups. Over time, it was discovered through science that it could infect any human being, regardless of race, color, age and sex they practice. It shows the importance of a team prepared

\footnotetext{
1 Trabalho realizado para a Disciplina de Atenção Integral à Saúde da Mulher do $6^{\circ}$ semestre do Curso de Enfermagem.

${ }^{2}$ Estudante do $7^{\circ}$ semestre do Curso de Enfermagem. E-mail: kelvinmmoncalves@ hotmail.com

${ }^{3}$ Estudante do $6^{\circ}$ semestre do Curso de Enfermagem: E-mail: jonas_quadros@ hotmail.com

${ }^{4}$ Estudante do $7^{\mathrm{a}}$ semestre do Curso de Enfermagem: E-mail: munah_saleh@hotmail.com

${ }^{5}$ Orientadora da Disciplina de Atenção Integral à Saúde da Mulher. Doutora em Enfermagem. Universidade Franciscana. E-mail: cmgdiaz12@gmail.com.
} 


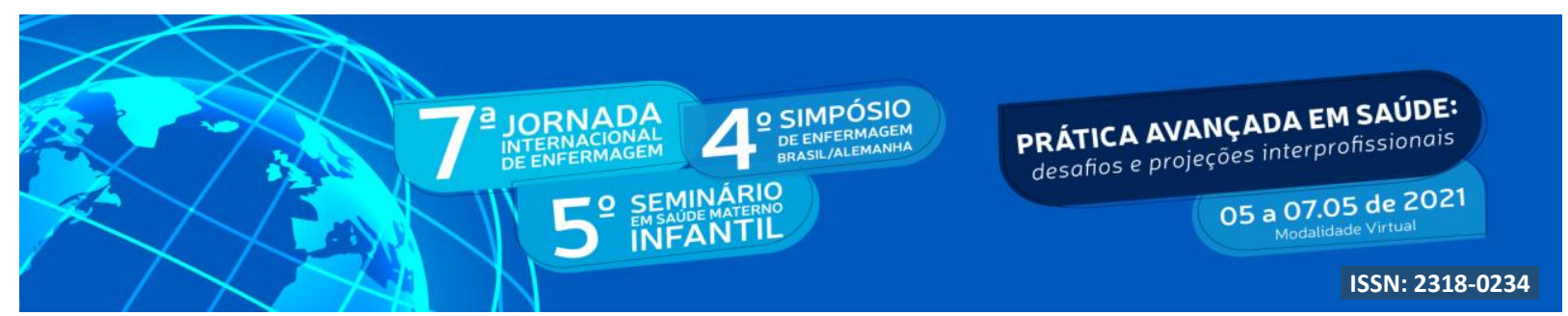

to meet the demands of mothers with positive serology, decision making at the time of delivery and the management of care for them during the delivery period and the puerperal period.

Key Words: Childbirth; HIV; Pregnant.

\section{INTRODUÇÃ̃O}

A gravidez é um período de grandes transformações para a mulher, para seu (sua) parceiro (a) e toda a família. Uma atenção pré-natal qualificada e humanizada ocorrem por meio de uma inserçao de condutas acolhedoras e sem intervenções desnecessárias e do fácil acesso aos serviços de saúde de qualidade e respeito, com ações integrativas que abranjam todos os níveis de atenção: promoção, prevenção e assistência à saúde da gestante e do recémnascido (RN) indo desde a Atenção Primária em Saúde (APS) ao atendimento hospitalar de alto risco (SOARES et al., 2013).

Desde que foi descoberta na década de 1980, a Síndrome da Imunodeficiência Humana - aids e o Vírus da Imunodeficiência Humana - HIV, como seu agente etiológico a teoria era que, tanto o HIV quanto a aids eram doenças restritas somente a determinados grupos, com comportamentos definidos de risco. As mulheres, especialmente as não usuárias de drogas e aquelas com parceiro fixo, não se percebiam vulneráveis à doença, porém, os resultados de estudos nas últimas décadas mudaram, e mostram um aumento significativo do número de casos notificados por transmissão sexual (VAZ; BARROS, 2002).

Estudos mostram que a origem do Vírus da Imunodeficiência Humana - HIV tenha acontecido por recombinação de uma versão original que infectava símios e que teria entrado no organismo de humanos caçadores de chimpanzés. Apesar de já ter sido isolado a partir de quase todos os fluídos corporais, apenas sangue, secreções genitais e, mais raramente, leite materno, implicam em sua transmissão (SOARES et al., 2014).

\section{OBJETIVO}

Conhecer o tratamento às gestantes, o manejo do parto e o aconselhamento durante o período puerperal em mulheres soropositivas sobre o olhar do profissional da saúde. 


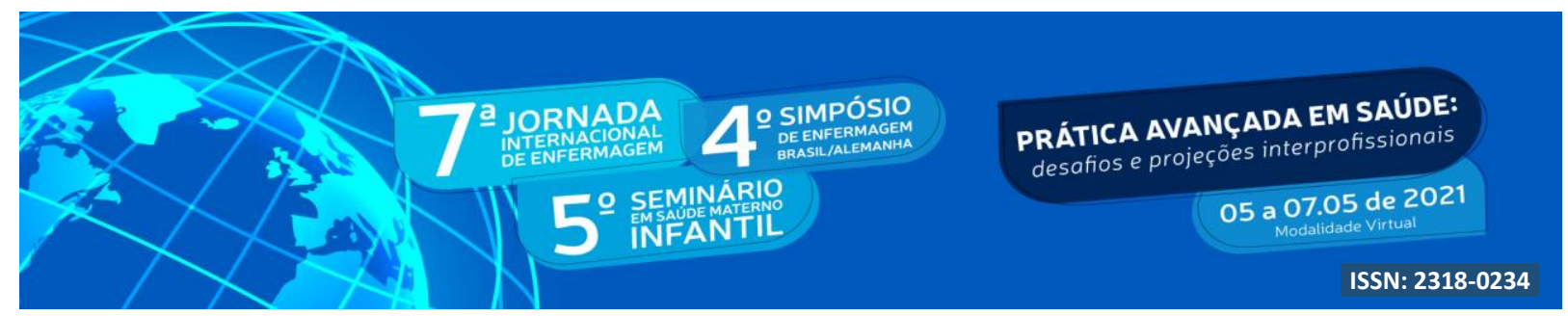

\section{METODOLOGIA}

O presente estudo trata-se de uma revisão bibliográfica não exaustiva, por meio de busca nas bases de dados Scielo sendo encontrados 11 artigos, PubMed com 2 artigos, periódicos da Universidade Federal do Amapá com 1 artigo e periódicos da Pontifícia Universidade Católica do Rio Grande do Sul contando também com 1 artigo, a busca foi feita com as seguintes palavras-chaves: gestantes, HIV e parto. E também foram utilizados 2 manuais técnicos do Ministério de Saúde de 2007 e 2012 que se relacionam diretamente com o tema proposto. Dos 13 artigos selecionados do Lilacs e PubMed foram excluídos 6 artigos que não enfocavam o HIV na gestação durante seus três períodos como principal questão.

Os resultados apontam para as seguintes questões: há ainda um grande aumento do número de infecção por HIV durante todos os períodos da vida e, principalmente na mulher gestante; falta de capacitação adequada às equipes de saúde para lidarem com pacientes gestantes soropositivas durante a gestação, parto e puerpério, mesmo com políticas públicas e metodologias destinadas para essa problemática no campo da saúde.

A reflexão sobre esse tema, assim como a criação de espaços de acolhimento e escuta sensível para com a mulher e para os profissionais de saúde são de fundamental importância para que essas questões recebam o cuidado e a atenção devida nos serviços de saúde.

\section{RESULTADOS E DISCUSSÃO}

De acordo com Brito (et al., 2001) a epidemia de aids no Brasil ela é caracterizada por três fases. A primeira fase, no início dos anos 80, caracterizou-se, principalmente, pela concentração de casos no eixo Rio de Janeiro/São Paulo e outras metrópoles localizadas no Sudeste e Sul, sendo restrita a certos grupos, como os homo e bissexuais e os receptores de sangue e hemoderivados.

A segunda fase, em meados da década de 1990, caracterizou-se pelo aumento dos números entre os usuários de drogas injetáveis (UDI) bem como o início de aumento dos casos por transmissão heterossexual (principalmente em parceiras de homens UDI). E por último, a terceira fase, se caracterizou pelo expressivo número de casos por transmissão entre indivíduos heterossexuais. Esse processo ficou conhecido como "heterossexualização do HIV", disseminando em todo o território nacional. 


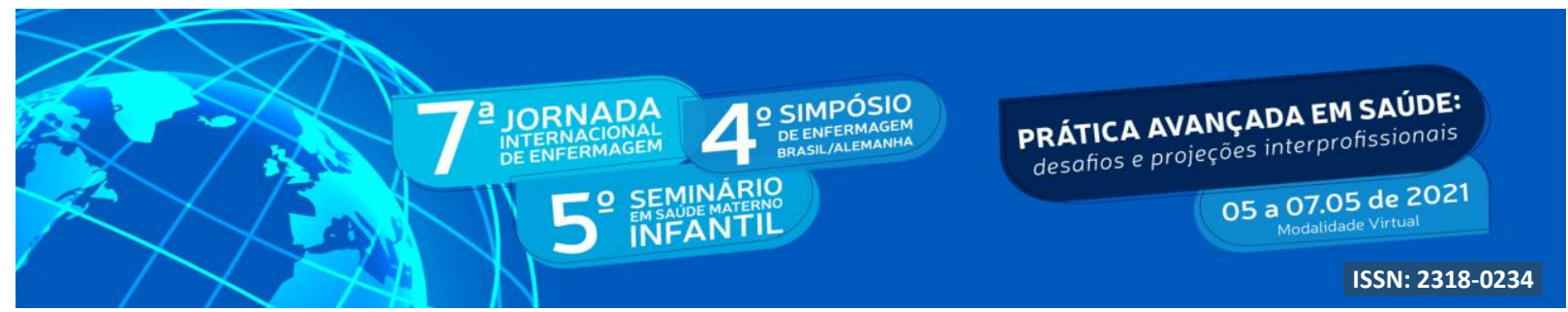

A aids é causada pelo vírus HIV, resultando numa queda progressiva da contagem de linfócitos T CD4+ e, com isso, começam a aparecer diversas afecções oportunistas, infecções ou até neoplasias, com um estado grave de imunodeficiência - o número de linfócitos $\mathrm{T}$ CD4+ deve estar abaixo de 350 células $/ \mathrm{mm}^{3}$ de sangue para ser considerada a existência da aids (SANTOS; SOUZA, 2012).

A transmissão materno-infantil (TMI), também denominada transmissão vertical (TV), pode ocorrer durante a gestação, parto e puerpério, sendo que cerca de $65 \%$ dos casos ocorrem durante o trabalho de parto. Dentre os fatores de TMI estão a carga viral materna; a ruptura prolongada das membranas amnióticas; a presença de infecções sexualmente transmissíveis (IST) e o tipo de parto; a prematuridade e o uso de drogas (BRITO et al., 2001).

O Ministério da Saúde preconiza a realização de, no mínimo, 6 consultas de pré-natal, com a realização de exames laboratoriais como $\mathrm{ABO} / \mathrm{Rh}$, Hemoglobina/Hematócrito, Glicemia de jejum, Urina tipo I, Sorologia para Toxoplasmose, Hepatite B e C, VDRL e antiHIV. O exame do anti-HIV deve ser realizado através do consentimento da gestante após aconselhamento pré-teste, sendo o resultado entregue após aconselhamento pós-teste. É preconizado na primeira consulta de pré-natal, com repetição no início do terceiro trimestre, sempre que possível e também no momento de internação para o parto (SOARES et al., 2013).

Estima-se que no Brasil há cerca de 0,4\% das gestantes soropositivas para o HIV, ou seja, 12.635 gestantes/parturientes portadoras do HIV/crianças expostas ao ano. A taxa de TV do HIV, sem qualquer intervenção, situa-se em torno de $25 \%$. No entanto, diversos estudos demonstram a redução da TMI do HIV para níveis de $1 \%$ a $2 \%$ por meio de intervenções preventivas, tais como: uso de antirretrovirais combinados, o parto por cirurgia cesariana eletiva, o uso de quimioprofilaxia com Zidovudina (AZT) na parturiente e no RN, e a não amamentação (BRASIL, 2012).

Durante a consulta, aspectos importantes devem ser questionados e abordados, tais como, comorbidades, condições e hábitos de vida. Esses aspectos devem ser levantados pela equipe multidisciplinar de saúde, conforme as particularidades de cada serviço. Como a infecção por HIV é uma doença de caráter sistêmico, é necessário além do exame físico geral, 


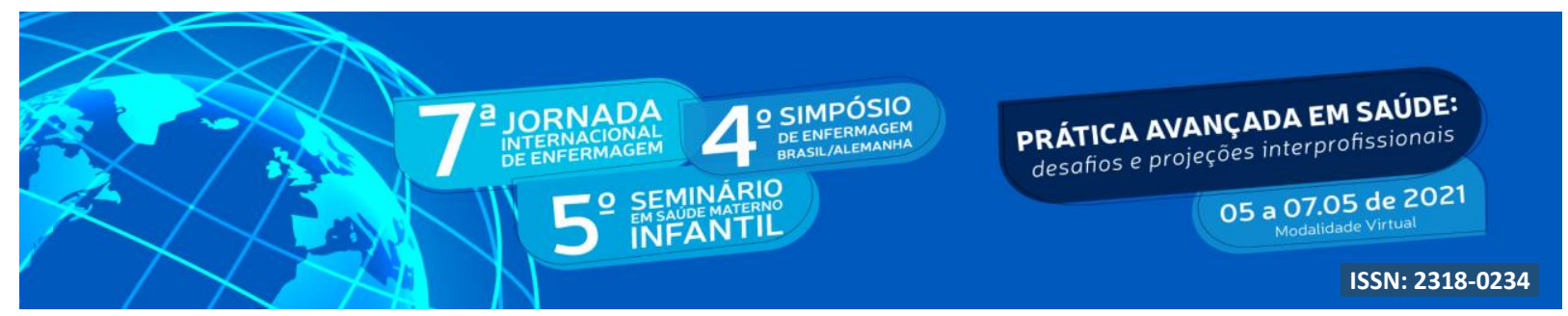

prestar atenção aos sinais clínicos sugestivos de manifestações da doença (BRASIL, 2012).

Dentre as condições clínicas que necessitam ser avaliadas durante as consultas de prénatal/ginecológica/de rotina, estão as consideradas dermatoses infecciosas, tais quais piodermites, angiomatose bacilar, sífilis e micobacteriose. Dermatoses fúngicas como a candidíase, dermatofitose, histoplasmose, criptococose e escabiose. Dermatoses não infecciosas, como por exemplo o prurigo associado ao HIV, foliculite eosinofílica, dermatite seborreica e farmacodermias e finalizando a avaliação clínica com as dermatoses neoplásicas, Sarcoma de Kaposi, linfoma e neoplasias epiteliais (ALONSO et al., 2003).

No que se refere ao exame de cabeça/pescoço devem ser avaliados a orofaringe (pesquisar candidíase oral e/ou leucoplasia pilosa), realizar, sempre que possível, a fundoscopia quando LT-CD4+ <200. Pesquisar linfonodopatias, hepatomegalia, esplenomegalia, massas palpáveis, sinais focais e estado cognitivo, examinar região perianal, pesquisando corrimentos, úlceras e lesões sugestivas de infecção por HPV ou neoplasias (BRASIL, 2012).

Pós avaliação e constatada a sorologia positiva deve se haver a avaliação profissional quanto a utilização da Terapia Antirretroviral (TARV). A indicação de TARV na gestação pode ter dois objetivos: profilaxia de TV ou tratamento de infecção pelo HIV. Se for por profilaxia de TV está recomendado para gestantes que não possuem indicação de tratar infecção pelo HIV, já que são assintomáticas (LT-CD4+>350 cél/ $/ \mathrm{mm}^{3}$ ) e o dano imunológico é pequeno ou ausente, havendo baixo risco de progressão para a AIDS. Essas mulheres não seriam candidatas a receber o TARV, caso não estivessem na gestação. A profilaxia deve ser suspensa após o parto (BRASIL, 2012).

Se o objetivo for para tratamento de infecção pelo HIV as mulheres que possuem repercussão clínica ou imunológica grave por infecção têm indicação de tratamento, independentemente da gravidez e em qualquer idade gestacional. Gestantes sintomáticas ou assintomáticas com contagem de LT-CD4+ $<350$ cél $/ \mathrm{mm}^{3}$ apresentam critérios para o início do tratamento (BRASIL, 2012).

Em mulheres com carga viral baixa ou zerada ou maior de 1.000 cópias/mL após 34 semanas de gestação, a cesárea eletiva na $39^{\text {a }}$ semana diminui o risco de TMI. Para gestantes com TARV e com suspensão de carga viral sustentada, caso não haja indicação de cesárea por 


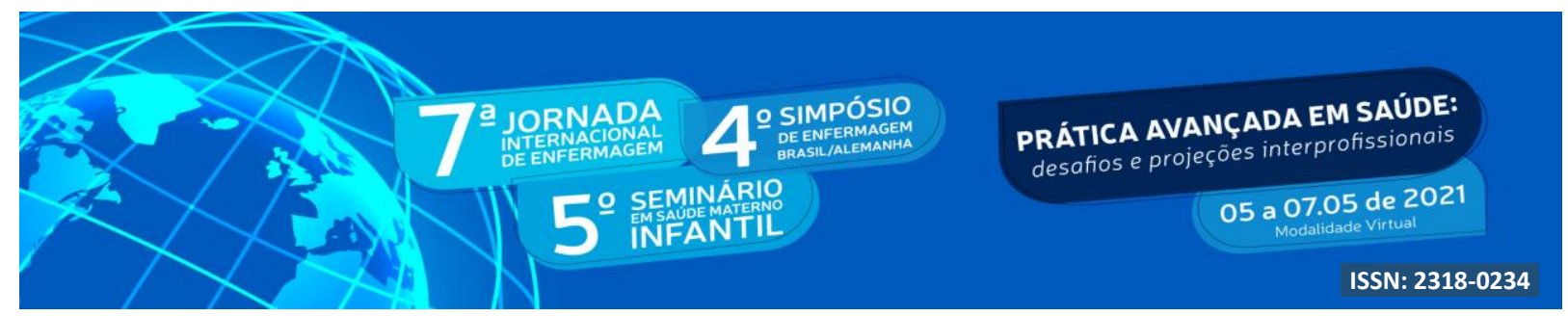

outro motivo, o parto vaginal é o mais indicado (LIMA et al., 2017).

A cesárea eletiva deve ser agendada para a $39^{\mathrm{a}}$ semana, evitando que a gestante entre em trabalho de parto e que ocorra a ruptura prematura das membranas corioaminióticas. $\mathrm{Na}$ eventualidade da gestante entrar em trabalho de parto antes da data prevista, desde que a dilatação cervical seja inferior a $3 \mathrm{~cm}$ e as membranas corioaminióticas estejam íntegras, a cesárea pode ser realizada (NÓBREGA et al., 2017).

Para as gestantes que chegam à maternidade e não iniciaram a TARV durante a gestação, a indicação de via de parto deverá levar em consideração a evolução do trabalho de parto e o prognóstico do tempo de evolução para o parto, assim como a probabilidade de intercorrências. Quando o trabalho de parto está em constante evolução, com prognóstico de nascimento rápido, deve ser indicado parto vaginal, empregando todos os cuidados para a redução de transmissão do HIV. E se o trabalho de parto estiver em sua fase inicial, com menos de $4 \mathrm{~cm}$ de dilatação e bolsa amniótica íntegra ou rota em menos de 2 horas, a cesárea deve ser indicada imediatamente (NÓBREGA et al., 2017).

De acordo com o Protocolo para a prevenção de transmissão vertical de Sífilis e HIV do Ministério da Saúde (2007), os cuidados gerais na hora do trabalho de parto e parto são:

1: Administrar AZT endovenosa desde o início do trabalho de parto até o nascimento e clampeamento do cordão;

2: Evitar procedimentos invasivos durante a gestação, no trabalho de parto e no parto, como a cordocentese, amniocentese, amniotomia, uso de fórceps e de vácuo extrator;

3: O trabalho de parto deve ser monitorado cuidadosamente, evitando toques desnecessários e repetitivos (usar partograma). Deve-se evitar que a parturiente permaneça com bolsa rota por muito tempo, visto que a taxa de transmissão vertical aumenta progressivamente após 4 horas de bolsa rota;

4: Em caso de ruptura precoce das membranas amnióticas, avaliar o prognóstico de evolução e usar Ocitocina, se necessário, para evitar um trabalho de parto demorado. Havendo contraindicações no uso da Ocitocina e prevendo um trabalho de parto prolongado, a cesárea pode ser indicada;

5: A episiotomia, no caso do parto vaginal, só será realizada após avaliação judiciosa de sua necessidade. Sendo realizada, a mesma deverá ser protegida por compressas umedecidas com Clorexidina. Manter a episiotomia coberta pela compressa umedecida deve ser tarefa de um auxiliar, visto ser impossível para um único profissional dar assistência ao parto e evitar o contato direto do nasciturno com a episiotomia;

6: Sempre que possível, proceder ao parto empelicado (retirada do RN mantendo as membranas amnióticas íntegras); 


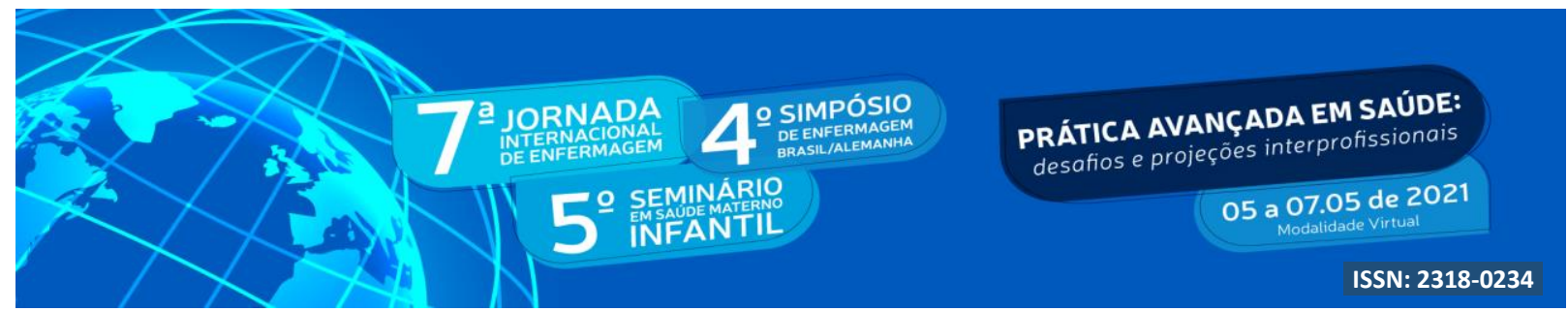

7: Usar ATB profilático, tanto na cesárea eletiva quanto naquela de urgência: dose única $\mathrm{EV}$ de $2 \mathrm{mg}$ de Cefalotina ou Cefazolina até 60 minutos antes do procedimento;

8: O uso de fármacos que aumentam a atividade uterina não está contraindicado, mas deve ser utilizado segundo os padrões de segurança já conhecidos. A aminiotomia artificial deve ser evitada, a menos que extremamente necessária. A ligadura do cordão umbilical deve ser imediata à expulsão do feto, não devendo ser executada, sob nenhuma hipótese, a ordenha do cordão;

9: Após o nascimento, a mulher e o recém-nascido, estando em boas condições de saúde, podem ser encaminhados para alojamento conjunto.

Estando em alojamento conjunto, começam-se as orientações por parte do profissional de saúde no período puerperal, que consiste em não amamentar o $\mathrm{RN}$ e isso deve ser pontuado e explicado para que a mulher entenda a gravidade do que essa ação pode acarretar, educação em saúde é fundamental para que a puérpera exerça autonomia e confiança para cuidar de seu filho e, além disso, ofertar a essa mãe uma educação continuada e acolhimento pelos serviços de saúde (ARAÚJO et al., 2012).

\section{CONCLUSÃO}

A realização do trabalho proporcionou um maior conhecimento sobre o manejo da paciente gestante portadora do vírus do HIV durante a gestação, parto e puerpério. A realização de um bom pré-natal, com realizações de exames periódicos, com avaliação clínica adequada, orientações precisas sobre a realidade do seu diagnóstico e sobre como se dará gestação, o parto e período puerperal sendo uma mãe soropositiva é de importante relevância para que ela tenha compreensão dos cuidados durante esses períodos e conhecimento acerca do que pode acontecer com o seu estado de saúde.

Um dos fatores identificados foi de que, a infecção por HIV na gestação continua sendo relevante fator de morbidade e preocupação entre as grávidas, com riscos de TV se não iniciado o TARV precocemente durante o pré-natal ou a não realização na hora do trabalho de parto. É recomendável que todas as gestantes sejam alvos de ações de diagnóstico e prevenção de TMI para o HIV, independente do seu risco para a infecção da doença.

O acolhimento, a educação permanente em saúde, a educação continuada e a percepção profissional para com essa paciente são as melhores estratégias para que ela mantenha sua 


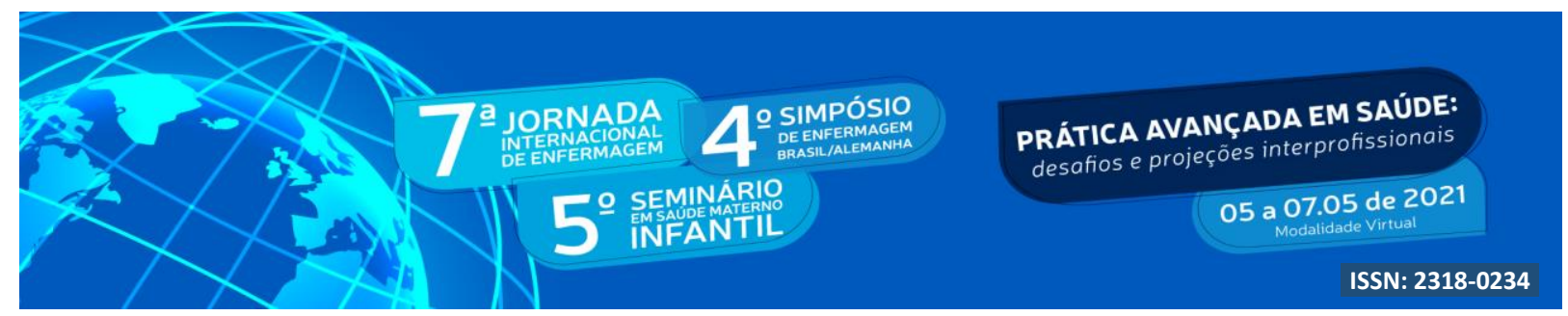

autonomia enquanto mãe/mulher e cumpra o seu papel da melhor maneira possível.

\section{REFERÊNCIAS}

ALONSO, N.; LUGO-SOMOLINOS, A.; TORRES-PAOLI, D.; SÁNCHEZ, J. L. Prevalence of skin disease in HIV-positive pregnant women. International Journal of Dermatology. 42. ed. p. 521-523. 2003.

ARAÚJO, C. L. F.; SIGNES, A. F.; ZAMPIER, V. S. de B.; O cuidado à puérpera com HIV/AIDS no alojamento conjunto: a visão da equipe de enfermagem. Escola Anna Nery, v.16, n.1. Rio de Janeiro. 2012.

BRASIL. Ministério da Saúde. Secretaria de Vigilância em Saúde Programa Nacional de DST e Aids. Protocolo para a prevenção de transmissão vertical de HIV e Sífilis. Manual de Bolso. Brasília - DF. 2007.

BRASIL. Ministério da Saúde. Secretaria de Atenção à Saúde. Departamento de Ações Programáticas Estratégicas. Gestação de Alto Risco - Manual Técnico $5^{\mathbf{a}}$ Edição. Brasília DF. 2012.

BRITO, A. M. de.; CASTILHO, E. A. de.; SZWARCWALD, C. L. Ainds e infecção pelo HIV no Brasil: uma epidemia multifacetada. Revista Sociedade Brasileira de Medicina Tropical, v.34, n.2. Uberaba. 2001.

LIMA, S. de S. de., SILVA, L. C. S.; SANTOS, M. V. dos.; MARTINS, J. P.; OLIVEIRA, M. C. de.; BRASILEIRO, M. E. HIV na gestação: pré-natal, parto e puerpério. Ciência \& Saúde, v.10, n.1. 2017.

NÓBREGA, M. V. D. da.; PAIVA, J. P.; FREITOSA, F. E. de L. Gestante HIV positivo: assistência ao parto. Protocolo Clínico. Universidade Federal do Ceará. 2017.

SANTOS, R. C. S. dos.; SOUZA, M. J. A. de. HIV na gestação. Estação Científica (UNIFAP), v.2, n.2, p.11-24. Macapá. 2012.

SOARES, R. S.; ARMINDO, R. D.; ROCHA, G. A imunodeficiência e o sistema imunitário. O comportamento em portadores de HIV. Arquivos de Medicina, v.28, n.4. Porto Alegre. 2014.

SOARES, M de L.; OLIVEIRA, M. I. C. de.; FONSECA, V. M.; BRITO, A. dos S.; SILVA, K. S. da. Preditores do desconhecimento do status sorológico de HIV entre puérperas submetidas ao teste rápido anti-HIV na internação para o parto. Ciência \& Saúde Coletiva, v.18, n.5, p.1313-1320. 2013. 


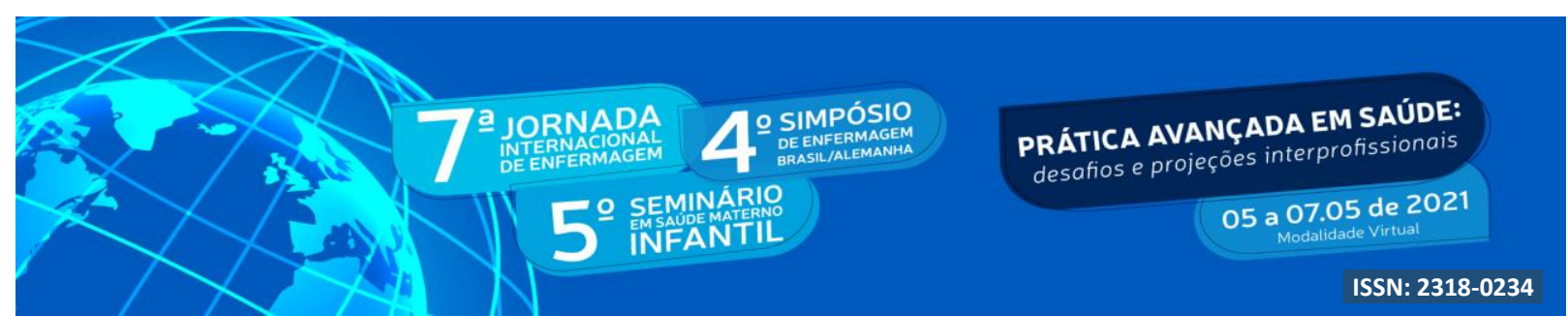

VAZ, M. J. R.; BARROS, S. M. O. de. Gestantes infectadas pelo HIV - Caracterização e Diagnósticos de Enfermagem. Acta Paulista de Enfermagem, v.15, n.2, p.9-17, 2002. 